University of Windsor

Scholarship at UWindsor

1998

\title{
Differential effectiveness of prevalent social work practice models: A meta-analysis
}

Kevin M. Gorey

University of Windsor

Bruce A. Thyer

Debra E. Pawluck

Follow this and additional works at: https://scholar.uwindsor.ca/socialworkpub

Part of the Social Work Commons

\section{Recommended Citation}

Gorey, Kevin M.; Thyer, Bruce A.; and Pawluck, Debra E.. (1998). Differential effectiveness of prevalent social work practice models: A meta-analysis. Social Work, 43 (3), 269-278.

https://scholar.uwindsor.ca/socialworkpub/18

This Article is brought to you for free and open access by the School of Social Work at Scholarship at UWindsor. It has been accepted for inclusion in Social Work Publications by an authorized administrator of Scholarship at UWindsor. For more information, please contact scholarship@uwindsor.ca. 
Differential effectiveness of prevalent social work practice models: A meta-...

Kevin M Gorey; Bruce A Thyer; Debra E Pawluck

Social Work; May 1998; 43, 3; ProQuest Nursing \& Allied Health Source

pg. 269

\title{
Differential Effectiveness of Prevalent Social Work Practice Models: A Meta-Analysis
}

\author{
Kevin M. Gorey, Bruce A. Thyer, and Debra E. Pawluck
}

This meta-analysis of 45 recently published (1990-1994) independent studies of social work's differential effectiveness by prevalent practice models builds on the more general findings of related meta-analyses that have estimated that three-quarters of the clients who participate in social work interventions do better

than the average client who does not. It found that the effectiveness of interventions based on different practice modelspersonal versus systemic-structural-was moderated by their primary focus for change. When the focus for change was clients themselves, personal orientations seemed more effective, whereas systemic-structural models were found to be more effective in supporting the change of other targets, such as environmental factors (structural change) rather than personal adaptation to environmental challenges. Key words: interventions; meta-analysis; practice theories;
social work practice

$\mathrm{W}$ ithin the past few decades, an increasing number of group outcome studies on the effectiveness of social work have been published. As this has occurred, various social workers have prepared narrative review articles that critically summarize their findings. Among the reviews of this type are Segal (1972); Fischer (1973); Reid and Hanrahan (1982); Sheldon (1986); MacDonald, Sheldon, and Gillespie (1992); Rubin (1985); and Thomlison (1984). Although such reviews have certainly performed a valuable professional service, their qualitative interpretive methods are often not replicable, and so they may leave the potentially potent alternative or confound explanation of reviewer bias essentially uncontrolled. The methodological refinement of meta-analysis, which calls for the specific explication of sampling (study selection) and analytic (effect size [ES] calculations) procedures, offers some control against such reviewer bias (Cooper, 1989; Wolf, 1986).

Although meta-analysis has long been used in the fields of medicine and psychology (for example, Smith \& Glass, 1977), to date only two meta-analytic studies of social work practice have been published. The first of these appeared in 1988 and was prepared by Videka-Sherman. 
Her conclusions were comforting and generous (Videka-Sherman, 1988): "social work intervention has a positive effect on outcome (p. 328) [and] ... An empirical basis on which to claim effectiveness of social work practice in mental health exists" (p. 329). Hogarty (1989) subsequently published a substantive critique of Videka-Sherman's study, claiming serious problems with the meta-analysis itself and inappropriate characterizations of social work practice, concluding, "this exercise not only resulted in questionable conclusions but also served to illustrate abiding problems in the design, methods, and analysis of social work research efforts" (p. 363). Given Hogarty's considerable stature as a clinical researcher in the field of chronic mental illness (Hogarty, 1991), the focal point of Videka-Sherman's study, his criticisms seemed to mute subsequent discussion of this initial meta-analytic study.

More recently, Gorey (1996) published a meta-analysis of contemporary social work effectiveness studies, covering those published from 1990 to 1994. Eighty-eight studies were selected from 13 journals, eight of which were affiliated with professional social work associations. Effect sizes were estimated using a metric called the $r$-index, interpretable as the Pearson's linear correlation coefficient, which provides an estimate of the strength of the social work intervention-outcome relationship. The focus of Gorey's original meta-analytic report was to compare the ESs generated by internal versus external evaluations of effectiveness.

A study that used social workers' assessments of the outcomes of their own practice was classified as an internal evaluation, whereas one using assessments by others unconnected with service delivery was labeled as an external evaluation. The mean $r$-index for all 88 studies was $.356(S D=.261, p<.001)$, permitting the conclusion that about 78 percent (based on conversion to another ES metric, Cohen's [1988] $U_{3}$ of 77.7 percent) of the clients who received social work intervention did better than the average client who did not. Moreover, others have replicated this overall finding among unpublished social work research sources (theses, dissertations, or conference proceedings); so mere publication bias is not likely as the explanation (de
Smidt \& Gorey, 1997; Grenier \& Gorey, in press). When the studies using internal evaluations of outcome were compared with external evaluations, it was found that although both produced positive ESs, the internal evaluations were significantly more favorable than the external [mean $r$ of .518 compared to $.186, t(86)=$ $7.93, p<.001]$. In other words, "social workers evaluating their own direct practice or their agencies' programs tended to report more favorable findings than evaluators who were not directly involved in the work" (Gorey, 1996, p. 124). This difference has important implications for the design of program evaluations: external evaluators unconnected with service provision will likely have more conservative assessments of outcomes.

\section{Differential Effectiveness of Social Work Practice Models}

Journal space limitations only allowed a partial report of Gorey's (1996) meta-analysis. His database permits an investigation of a number of other interesting questions, one of which is the focus of the meta-analysis reported in this article: Do social work interventions derived from different theoretical orientations produce different treatment outcomes (that is, effect sizes)? To the extent that social work makes use of existing empirically based knowledge, the fact that particular models of intervention are shown to be more effective than some others has considerable implications for social work education and practice. The data are not clear in this matter. In the general field of psychotherapy, some meta-analyses seem to have found that an intervention's theoretical orientation has little association with ES (for example, Miller \& Berman, 1983), whereas others have found that behavioral and cognitive-behavioral interventions yield larger ESs than psychodynamic or humanistic approaches to practice (Andrews \& Harvey, 1981; Shapiro \& Shapiro, 1982; Smith, Glass, \& Miller, 1980).

Within social work, Videka-Sherman (1988) concluded that "behavioral models do not dominate the empirical base of social work" ( $p$. 329), whereas other researchers have concluded much the opposite (MacDonald et al., 1992; Reid \& Hanrahan, 1982; Rubin, 1985; Thomlison, 
1984). Inasmuch as Videka-Sherman did not report ESs by the theoretical orientation of the studies she evaluated, it is difficult to ascertain the validity of her contention that behavioral approaches are not clearly superior to other models of social work. On the other hand, there seems to be a burgeoning advocacy in support of the possible stronger empirical foundations of more progressive or radical social work perspectives (Collins, 1986; Compton \& Galaway, 1989; Germain \& Gitterman, 1996; Lewis, 1992; McMahon, 1990; Meyer, 1993; Mullaly, 1993; Tolson, Reid, \& Garvin, 1994). Accordingly, we conducted an analysis of the Gorey (1996) database to explore possible intervention effectiveness differences by theoretical orientation.

\section{Methods}

\section{Study Selection}

Gorey (1996) originally selected studies (19901994) from eight social work journals affiliated with professional social work associations (Social Work, Social Work Research [formerly Social Work Research \& Abstracts], Health \& Social Work, Journal of Social Work Education, Australian Social Work, British Journal of Social Work, Canadian Social Work Review, and Social Work in Education), three social welfare and social work practice research-oriented journals (Journal of Social Service Research, Social Service Review, and Research on Social Work Practice), and two exemplars of prevalent fields of practice (Gerontologist and the Journal of Family Issues). Subject key words for this search were assessment, benefit, effect, effectiveness, efficacy, evaluation, follow-up, and outcome.

From the conceptually relevant studies, only 88 (31.5 percent) that operationalized such that an indication of their effect size was calculable were included in the original meta-analysis. The conceptually relevant although empirically deficient studies were excluded primarily because they did not report within-group variability descriptors (for example, group standard deviations [SDS]) or statistics that accounted for such phenomenon (for example, $F$ ratio, $t$ test, or $\left.\chi^{2}\right)$. Average between-group differences are largely uninterpretable without such information.
Beginning with the original sample of 88 published studies reported by Gorey (1996), we used these additional inclusion criteria: first author is a social worker or the practitioners engaged in the study were social workers ( 84 percent of the original sample met this criterion); the authors studied practice with individuals, small groups, or families (excluded program evaluations or studies with units of analysis larger than individuals, such as communities); and the authors used a group research design (single-client designs were excluded). Also, studies that merely assessed "client satisfaction" were excluded. We believe that the use of these additional selection criteria yields a generalizable pool of outcome studies that more closely approximate assessments of interpersonal social work practice. The 45 studies thus selected for the present analysis did not differ significantly from the original (Gorey, 1996) on their representation of major design (pre-, quasi- and true experimental and sample size) and intervention characteristics (individual, small group, and family and duration); they did not differ significantly on their overall conclusion about the effectiveness of social work interventions (mean $r$-index for all 45 studies was $.319, S D=.228$, range from -.21 to .88 , combined $p<.001, U_{3}=$ 75.0 percent).

\section{Determination of Theoretical Orientation}

Two independent coders, blind to this review's purposes, read the Methods section of each of the 45 selected studies and categorized them into one of the following theoretical orientations or practice models: cognitive-behavioral, psychosocial, and psychodynamic (collectively labeled personal orientations); generalist problem solving and task centered (labeled generalist frameworks); family systems, general systems, and ecosystems (labeled systemic orientations); or feminist and person-inenvironment (emphasis on environment, labeled radical-structural orientations). In cases where interventions were designed around multiple practice models, the primary one was coded (for example, most in-text discussion or citations or experimental, rather than comparison condition). Interrater concordance for the subcategories was 91 percent; at 
the level of the four grouped labels it was 96 percent.

The identical effect size metric, the $r$-index, used by Gorey (1996) was used in the present study. It focuses on the strength of the intervention-outcome association (interpretable as Pearson's linear correlation coefficient), and so is the most appropriate ES metric for analyzing studies that for the most part ( 70 percent), as in the present case, are not true experiments (Cooper, 1989; Glass, McGaw, \& Smith, 1981; Rosenthal, 1984; Wolf, 1986). The $r$-index was calculated for each of the 45 independent studies. Pearson's $r$-a scale-free effect size metricis calculable from a variety of outcome statistics (group $M s$ and SDs, $t$ test, $F$ ratio, $\chi^{2}$, and $p$ level with group $n s$ ), and thus allows for ease of across-study comparison and summary. Finally, Cohen's (1988) $U_{3}$ statistic, itself calculable from the $r$-index, was used as an index of practical significance. It is an intuitively appealing metric, which compares all of an intervention group members' scores on a dependent measure at posttest (for example, with a comparison group's average score).

\section{Results}

The primary theoretical orientations represented among the 45 selected studies may generally be conceptualized along a historical continuum; from earlier, more traditional "borrowed" psychological and psychiatric theories, which typically emphasize the need for individuals with problems to change, to more recently postulated "radical" perspectives, which more typically identify problem environments (that is, the structures of society) as the more appropriate targets of change (Table 1 ). Between these two extremes are what may be considered the heart of progressive, uniquely social work theorizing over the past 25 years, underscoring the profession's commitment to generalist understanding of the systemic relationships between individuals and environments.

The descriptive statistics outlined in Table 1 are themselves very telling. Most strikingly, based on this review's sample of studies, approximately half ( 56 percent, 25 of 45 studies) of the empirical social work practice base makes reference to essentially psychological theories about the interrelationship of thoughts, feelings, and other

\section{Table 1}

\section{Theoretical Orientations in the Research Literature on the Effectiveness of Social Work Practice Interventions: Average Effect Sizes ( $r$-Index)}

\begin{tabular}{|c|c|c|c|c|}
\hline \multirow[b]{2}{*}{ Theories } & \multirow[b]{2}{*}{ Studies $(N=45)$} & \multicolumn{3}{|c|}{$r$-Index } \\
\hline & & $\%$ & $M$ & $S D$ \\
\hline Personal orientations & 25 & 55.5 & .378 & .203 \\
\hline Cognitive-behavioral $^{a}$ & 22 & 48.9 & .386 & .214 \\
\hline Psychosocial & 2 & 4.4 & .311 & .113 \\
\hline Psychodynamic & 1 & 2.2 & .340 & \\
\hline Generalist frameworks & 10 & 22.2 & .274 & .267 \\
\hline Generalist problem solving ${ }^{b}$ & 8 & 17.8 & .255 & .278 \\
\hline Task centered & 2 & 4.4 & .370 & .283 \\
\hline Systemic orientations & 8 & 17.8 & .190 & .095 \\
\hline Family systems & 5 & 11.2 & .174 & .102 \\
\hline General systems & 2 & 4.4 & .260 & .085 \\
\hline Ecosystems & 1 & 2.2 & .130 & \\
\hline Radical-structural orientations & 2 & 4.4 & .540 & .014 \\
\hline Feminist & 1 & 2.2 & .530 & \\
\hline Person-in-environment ${ }^{c}$ & 1 & 2.2 & .550 & \\
\hline
\end{tabular}

NoTE: The combined probability for each of the four major theoretical orientations was minimally significant at $p<$ .01 (Rosenthal, 1978).

ancludes theories categorically described as behavioral, cognitive, or cognitive-behavioral.

'One study also made mention of problem-solving work within a "strengths perspective."

'Emphasis was on environmental (structural) interventions, rather than on personal adaptation to environmental challenges. 
individual behaviors with personal problemsin-living; the remainder are more representative of systemic social work orientations.

\section{Theoretical Orientation by Target System Interaction}

No main effect of theoretical orientation was observed, that is, none of the mean $r$-indices displayed in Table 1 differed significantly from one another (at the level of minor [ 10 categories, $F(9,35)=0.91$, not significant] or major categorizations [ four categories, $F(3,41)=2.42$, not significant), even when using a liberal exploratory criterion of $p<.10$. To bolster statistical power, each major theoretical categorization was compared to the other three combined categories; none of the comparisons yielded even liberally significant between-group differences. The nonsignificance of the difference between various practice models' effects is perhaps not all that surprising when one considers the extraordinary variability among the interventions, clients, and problems represented in the studies reviewed.

To provide some measure of control for such extraneous influences, the following analysis was accomplished. First, eight studies were excluded: those assessing work with other than traditional clients, such as interventions with social work students or with social workers themselves and very brief (one day or one time [video]) merely educational workshops. Then the average effectiveness of personal versus other (generalist, systemic, and structural) theoretical orientations was compared across levels of primary interventive focus for change: the clients themselves (client system) or some other target system. It should be noted that these theory categories (personal versus other) did not differ significantly on any of the originally coded research design rigor characteristics (pre- to true experiment, sample size, type of comparison group, use of random selection, and internal or external evaluation), and so their comparison on interventive effects cannot be confounded by them.

A practically significant moderation of the interventive effect or theory by target system interaction was observed (Table 2). When the primary focus of an intervention's change effort was the individual clients themselves, personal theoretical orientations (predominantly cognitive-behavioral) faired better ( $U_{3}$ of 79.8 percent [fourfold as many moderate to large effects, prevalence ratio $=3.93, \chi^{2}(1,24)=7.98, p$ $<.05$ ] compared to 69.6 percent), whereas, among interventions designed to positively affect individuals, small groups, or families

\begin{tabular}{|c|c|c|}
\hline \multicolumn{3}{|c|}{$\begin{array}{l}\text { The Effectiveness of Social Work Practice } \\
\text { Interventions by Theoretical Orientation } \\
\text { and the Primary Focus of the Work }\end{array}$} \\
\hline $\begin{array}{l}\text { Primary } \\
\text { Interventive Focus }\end{array}$ & \multicolumn{2}{|c|}{$\begin{array}{l}\text { Theoretical } \\
\text { Orientation }\end{array}$} \\
\hline ES Statistics & Personal & $\begin{array}{l}\text { Systemic- } \\
\text { Structural }^{\text {a }} \\
\end{array}$ \\
\hline Client system & & \\
\hline No. of studies & 14 & 10 \\
\hline Mean $r^{* *}$ & .385 & .249 \\
\hline SL & .175 & .236 \\
\hline $\begin{array}{l}\text { Cohen's } \mathrm{U}_{3} \\
r>.30^{\mathrm{b}}\end{array}$ & $\begin{array}{c}79.8 \% \\
11 \text { of } 14,78.6 \%\end{array}$ & $\begin{array}{c}69.6 \% \\
2 \text { of } 10,20.0 \%\end{array}$ \\
\hline $\begin{array}{l}\text { Prevalence ratio } \\
\qquad(95 \% \mathrm{CI})^{c} \\
\text { Other target system }\end{array}$ & \multicolumn{2}{|c|}{$3.93(1.53,10.10)$} \\
\hline $\begin{array}{l}\text { No. of studies } \\
\text { Nor target system }\end{array}$ & 5 & 8 \\
\hline Mean $r^{*}$ & .206 & .341 \\
\hline$S L$ & .112 & .196 \\
\hline $\begin{array}{l}\text { Cohen's } \mathrm{U}_{3} \\
r>.30^{\mathrm{b}}\end{array}$ & $\begin{array}{c}66.2 \% \\
1 \text { of } 5,16.7 \%\end{array}$ & $\begin{array}{l}76.6 \% \\
8.83 .3 \%\end{array}$ \\
\hline $\begin{array}{l}\text { Prevalence ratio } \\
\qquad(95 \% \mathrm{CI})^{c}\end{array}$ & $4.99(1.0$ & $00,24.90)$ \\
\hline
\end{tabular}

NoTE: $\mathrm{ES}=$ effect size; $\mathrm{CI}=$ confidence interval. ${ }^{a}$ Generalist, systemic, and structural orientations. ${ }^{b}$ Moderate to large effect (Cohen, 1988).

'Prevalence ratio of moderate to large effects with $\chi^{2}$ test-based 95 percent confidence interval (Miettinen, 1976).

'Interventions designed to positively affect individuals, small groups, or families through change of another target system, for example: referral strategies (social welfare system); transfer or other discharge policies (hospitals); systemic inpatient-outpatient boundaries (organizations serving alcoholics and substance abusers); lifespace social support interventions; and other interventions targeted on other than the identified client's family systems (family members of nursing home "patients," parents of children with developmental disabilities, or families of newly adopted children). $* p<.20 . * * p<.10$ (approach significance, one-way ANOVA). 
through change to another target system, more traditional social work models, including systemic-structural ones faired better $\left(U_{3}\right.$ of 76.6 percent [fivefold as many moderate to large effects, $\left.\chi^{2}(1,13)=3.88, p<.05\right]$ compared to 66.2 percent $)$.

\section{Discussion}

This meta-analytic exploration of an extant social work research database (journals dated 1990-1994) (Gorey, 1996) found that the overall effectiveness of interventions based on different practice models (personal versus systemic-structural) is moderated by their interventive foci for change. In a significant sense, the different models seem to do best what they were designed to do; personal orientations seem most supportive of client change, whereas systemic-structural models were found to be most effective in supporting the change of other interventive targets.

Earlier reviews of social work outcome studies found that cognitive-behavioral social work methods were the single most represented theoretical orientation being tested. Moreover, it was these same behavioral methods that produced the most positive outcomes (see for example, MacDonald et al., 1992; Reid \& Hanrahan, 1982; Rubin, 1985; Thomlison, 1984). The present study documents the continuing impressive representation of cognitivebehavioral models of social work practice among the outcome studies published between 1990 and 1994. Fully 22 of the 45 studies ( 49 percent) made use of these models, far exceeding any other orientation. However, in exploring main interventive effects, the present review did not find evidence in support of their differential effectiveness. In fact, it did find evidence strongly in support of the notion that when the target of change is more progressively defined as some element of the environment or the structures of society, then social work models such as generalist problem solving, task-centered, systemic, and radical ones are significantly more effective than cognitive-behavioral ones. For more radical work - that is, where the focus is not so much on client adaptation to environmental challenges but on mutual clientworker strategizing to change another target system (the environment itself [structural change]) - the prevalence of moderate to large interventive effects may be fivefold greater among generalist, systemic, or radical social work orientations compared with cognitivebehavioral ones.

Clearly though, the empirical social work practice knowledge base is much greater for cognitive-behavioral models. We therefore respectfully call on our researcher-practitioner colleagues, particularly those working with models less well represented, to routinely report what they are learning with their clients. Unless more progressive systemic-structural social work models are empirically studied and the findings of such studies reported in the mainstream professional press, it is likely that future funding opportunities for them and thus for their great potential for preventive and therapeutic benefits will be lost to future clients.

Furthermore, we do not believe that a commitment to such empirical observation necessarily requires a concomitant adherence to logical positivism. Social workers valuing more relativistic positions may still observe the truth of their work with clients. More subjective, client-worker developed, qualitative outcome measures may be used to good effect, along with vote-count methods of synthesizing findings (Hedges \& Olkin, 1982).

This review supports the notion that feminist social workers, radicalist-structuralists, and progressive, generalist social workers working within a person-in-environment framework do very effective work, particularly when the problem is defined as one that transcends the individual - that is, the problem does not reside somewhere "under the client's skin." However, political adversaries will continue to have little difficulty in refuting this notion unless the profession continues to build the knowledge base in support of it.

\section{Future Primary and Integrative Research Needs}

Cognitive-behavioral interventions and other personal orientations to practice were found to be three times more prevalent than any other method among published empirical research on social work practice, yet no substantive evidence 
for their greater effectiveness was observed. On the other hand, a nonsignificant trend indicative of the possible greater effectiveness of radical-structural social work methods, including feminist ones, was observed. However, these were the least-reported methods. It should be recalled that although this review included only those studies for which an effect size was calculable (approximately two-thirds of the conceptually relevant studies were excluded on this basis), it did not exclude any merely on the basis of their measures or research design. In fact, nearly half of its sample of studies used qualitative measures, many of which were clientworker constructed, and the vast majority of them could be characterized as other than experimental designs (Gorey, 1996).

Some may argue that effect size calculation procedures are not congruent with more naturalistic methods of work with clients. We disagree with this notion; meta-analytic procedures do not necessarily have to be highly quantitative in their approach. Effects are calcu lable, for example, from a qualitative study that dichotomizes a worker-client-constructed scale of goal attainment (yes or no) and simply reports the proportion meeting their goals (implicit comparison group-none [by definition] had met such goals prior to their experience of the work). Even such a naturalistic study allows a researcher to calculate a test statistic (for example, a chi-square test, from which the $r$-index is calculable) and minimally rule out sampling variability or the play of chance as a potent alternative or confound explanation for the intervention's hypothesized effectiveness. Certainly, if for no other reason than political expedience, all social worker researcher-practitioners, be they logical positivists or adherents to more heuristic-relativistic paradigms, ought to be concerned with such minimal validation of their work with the clients they serve.

We are aware through our own practice research of the possibly greater effectiveness of radical-structural interventions, based on feminist and oppression theories, compared with more traditional social work models (for example, generalist problem solving) for work with extremely traumatized clients. For example, recent evaluations of feminist social work with female survivors of childhood sexual abuse have found somewhat larger effects $\left(U_{3} \mathrm{~s}\right.$ of approximately 90 percent) than those observed for generalist social work with similarly abused clients [ $U_{3}$ s of approximately 75 percent; $\left.\chi^{2}(1,223)=4.23, p<.05\right]($ de Jong $\&$ Gorey, 1996; Preyde \& Gorey, 1997; Richter, Snider, \& Gorey, 1997). More research is needed on specific feminist interventive effects for work with these and other specific clients in specific contexts. Moreover, we are unaware of a single integrative review on the topic of feminist social work practice. The present review, by sampling from journals affiliated with professional social work associations, more effectively targeted genuine social work practice; one-third of the previously reviewed research in this field arose from journals affiliated with the American Psychological Association or the American Psychiatric Association.

This review also attempted to oversample from what may be generally characterized as "research-oriented" journals. Another integrative review that focuses on more "practiceoriented" journals, perhaps including all those with specific mission statements that mention radical-structural, including feminist principles, would go a long way toward fully reviewing our profession's knowledge base for practice. Most important, in more fully explicating what is as yet unknown but hypothesized to be important, such a proposed review, along with the present one, would provide a clear plan for the next generation of social work practice research.

\section{References}

Asterisked references are included in the metaanalysis.

Andrews, G., \& Harvey, R. (1981). Does psychotherapy benefit neurotic patients? Archives of General Psychiatry, 38, 1203-1208.

*Auslander, G. K., \& Soskolne, V. (1993). The administrative and posthospital care outcomes of discharge planning: Preliminary results of an experimental intervention. Journal of Social Service Research, 17, 99-117.

* Barber, J. G. (1992). Evaluating parent education groups: Effect on sense of competence and social isolation. Research on Social Work Practice, 2, 2838. 
${ }^{*}$ Benbenishty, R., Ben-Zaken, A., \& Yekel, H. (1991). Monitoring interventions with young Israeli families. British Journal of Social Work, 21, 143155.

${ }^{*}$ Bielenberg, L. T. (1991). A task-centered preventive group approach to create cohesion in the new stepfamily: A preliminary evaluation. Research on Social Work Practice, 1, 416-433.

${ }^{*}$ Carlo, P. (1993). Parent education vs. parent involvement: Which type of efforts work best to reunify families? Journal of Social Service Research 17, 135-150.

Cohen, J. (1988). Statistical power analysis in the behavioral sciences (2nd ed.). Hillsdale, NJ: Lawrence Erlbaum.

Collins, B. G. (1986). Defining feminist social work. Social Work, 31, 214-219.

Compton, B. P., \& Galaway, B. (1989). Social work processes (4th ed.). Belmont, CA: Wadsworth.

Cooper, H. M. (1989). Integrating research: A guide for literature reviews (2nd ed.). Newbury Park, CA: Sage Publications.

* Dallaire, N., \& Chamberland, C. (1994). La pertinence du programme parents efficaces auprès de parents bénéficiant du soutien d'un groupe parentraide une étude préliminaire [Relevance of the "effective parenting" program for parents benefiting from the support of a "parentraide" group: A preliminary study]. Canadian Social Work Review, 11, 67-88.

de Jong, T. L., \& Gorey, K. M. (1996). Short-term versus long-term group work with female survivors of childhood sexual abuse: A brief metaanalytic review. Social Work with Groups, 19, 1927.

de Smidt, G. A., \& Gorey, K. M. (1997). Unpublished social work research: Systematic replication of a recent meta-analysis of published intervention effectiveness research [Research Note]. Social Work Research, 21, 58-62.

${ }^{*}$ Dziegielewski, S. F. (1991). Social group work with the family members of elderly nursing home residents with dementia: A controlled evaluation. Research on Social Work Practice, 1, 358-370.

*Edleson, J. L., \& Syers, M. (1991). The effect of group treatment for men who batter: An 18month follow-up study. Research on Social Work Practice, 1, 227-243.

Fischer, J. (1973). Is casework effective? A review. Social Work, 18, 5-20.
*Frey, D. E., Kelbey, T. J., Durham, L., \& James, J. S. (1992). Enhancing the self-esteem of selected male nursing home residents. Gerontologist, 32, 552-557.

${ }^{*}$ Gammon, E. A., \& Rose, S. D. (1991). The coping skills training program for parents of children with developmental disabilities: An experimental evaluation. Research on Social Work Practice, 1, 244-256.

Germain, C. B., \& Gitterman, A. (1996). The life model of social work practice: Advances in theory and practice (2nd ed.). New York: Columbia University Press.

${ }^{*}$ Gibbons, J. (1991). Children in need and their families: Outcomes of referral to social services. British Journal of Social Work, 21, 217-227.

Glass, G. V., McGaw, B., \& Smith, M. L. (1981). Meta-analysis in social research. Beverly Hills, CA: Sage Publications.

Gorey, K. M. (1996). Effectiveness of social work intervention research: Internal versus external evaluations. Social Work Research, 20, 119-128.

${ }^{*}$ Green, R. G., \& Vosler, N. R. (1992). Issues in the assessment of family practice: An empirical study. Journal of Social Service Research, 15, 1-19.

Grenier, A. M., \& Gorey, K. M. (in press). The effectiveness of social work with older people and their families: A meta-analysis of conference proceedings [Research Note]. Social Work Research.

*Hanson, M., Cancel, J., \& Rolon, A. (1994). Reducing AIDS risk among dually disordered adults. Research on Social Work Practice, 4, 14-27.

${ }^{\star}$ Hanson, M., Foreman, L., Tomlin, W., \& Bright, Y. (1994). Facilitating problem drinking clients' transition from inpatient to outpatient care. Health er Social Work, 19, 23-28.

${ }^{*}$ Hawkins, J. D., Jenson, J. M., Catalano, R. F., \& Wells, E. A. (1991). Effects of a skills training intervention with juvenile delinquents. Research on Social Work Practice, 1, 107--121.

Hedges, L., \& Olkin, I. (1982). Vote-counting methods in research synthesis. Psychological Bulletin, $88,359-369$.

${ }^{*}$ Hepler, J. B. (1994). Evaluating the effectiveness of a social skills program for preadolescents. Research on Social Work Practice, 4, 411-435.

Hogarty, G. E. (1989). Meta-analysis of the effects of practice with the chronically mentally ill: $A$ critique and reappraisal of the literature. Social Work, 34, 363-373. 
Hogarty, G. E. (1991). Social work practice research on severe mental illness: Charting a future. $R e^{-}$ search on Social Work Practice, 1, 5-31.

*Ingersoll-Dayton, B., Chapman, N., \& Neal, M. (1990). A program for caregivers in the workplace. Gerontologist, 30, 126-130.

* Kissman, K. (1992). Parent skills training: Expanding school-based services for adolescent mothers. Research on Social Work Practice, 2, 161 171 .

*Larkin, J. P., \& Hopcroft, B. M. (1993). In-hospital respite as a moderator of caregiver stress. Health \& Social Work, 18, 132-138.

Lewis, E. (1992). Regaining promise: Feminist perspectives for social group work practice. Social Work with Groups, 15, 271-284.

*Luptak, M. K., \& Boult, C. (1994). A method for increasing elders' use of advance directives. Gerontologist, 34, 409-412.

MacDonald, G., Sheldon, B., \& Gillespie, J. (1992). Contemporary studies of the effectiveness of social work. British Journal of Social Work, 22, 615643.

*Magen, R. H., \& Rose, S. D. (1994). Parents in groups: Problem solving versus behavioral skills training. Research on Social Work Practice, 4, 172 191.

*Mancoske, R. J., Standifer, D., \& Cavley, C. (1994). The effectiveness of brief counseling services for battered women. Research on Social Work Practice, 4, 53-63.

McMahon, M. O. (1990). The general method of social work practice: A problem-solving approach (2nd ed.). Englewood Cliffs, NJ: Prentice Hall.

Meyer, C. H. (1993). Creating our own roles. Affilia, $8,245-246$.

Miettinen, O. S. (1976). Estimability and estimation in case-referent studies. American Journal of Epidemiology, 103, 226-235.

Miller, R. C., \& Berman, J. S. (1983). The efficacy of cognitive behavior therapies: A quantitative review of the research evidence. Psychological Bulletin, 94, 39-53.

Mullaly, R. (1993). Structural social work: Ideology, theory, and practice. Toronto: McClelland \& Stewart.

*Nugent, W. R., Carpenter, D., \& Parks, J. (1993). A statewide evaluation of family preservation and family reunification services. Research on Social Work Practice, 3, 40-65.
*O'Neal, G. S. (1993). Preventing conflict: Encouraging collaboration among students, faculty, and family. Social Work in Education, 15, 83-89.

Preyde, M. R., \& Gorey, K. M. (1997). Multi-method feminist social work with challenged women: $A$ retrospective study of effectiveness. Social Worker, 65, 129-136.

* Raynor, P., \& Vanstone, M. (1994). Probation practice, effectiveness and the non-treatment paradigm. British Journal of Social Work, 24, 387-404.

*Reid, W. I., Bailey-Dempsey, C. A., Cain, E., Cook, T. V., \& Burchard, J. D. (1994). Cash incentives versus case management: Can money replace services in preventing school failure? Social Work Research, 18, 227-236.

Reid, W. J., \& Hanrahan, P. (1982). Recent evaluations of social work: Grounds for optimism. Soicial Work, 27, 328-340.

* Ressler, L. E. (1991). Improving elderly recall with bimodal presentation: A natural experiment of discharge planning. Gerontologist, 31, 364-370.

Richter, N. L., Snider, E., \& Gorey, K. M. (1997). Group work intervention with female survivors of childhood sexual abuse. Research on Social Work Practice, 7, 53-69.

${ }^{*}$ Rosen, A. (1993). Correction of worker's personal versus environmental bias in formulation of client problems. Social Work Research \& Abstracts, $29(4), 12-17$.

Rosenthal, R. (1978). Combining results of independent studies. Psychological Bulletin, 85, 185-193.

Rosenthal, R. (1984). Meta-analytic procedures for social research. Beverly Hills, CA: Sage Publications.

Rubin. A. (1985). Practice effectiveness: More grounds for optimism. Social Work, 30, 469-476.

* Rubin, A. B., Franklin, C., \& Selber, K. (1992). Integrating research and practice into an interviewing skills project: An evaluation. Journal of Social Work Education, 28, 141-152.

* Saunders, R. I., \& Saunders, D. N. (1993). Social work practice with a bulimic population: A comparative evaluation of purgers and nonpurgers. Research on Social Work Practice, 3, 123-136.

*Schilling, R. F., Koh, N., Abramovitz, R., \& Gilbert, L. (1992). Bereavement groups for inner-city children. Research on Social Work Practice, 2, $405-419$

*Scott, M. J., \& Stradling, S. G. (1991). The cognitive-behavioural approach with depressed clients. British Journal of Social Work, 21, 533-544. 
Segal, S. P. (1972). Research on the outcome of social work therapeutic interventions: A review of the literature. Journal of Health and Social Behavior, 13, 3-17.

Shapiro, D. A., \& Shapiro, D. (1982). Meta-analysis of comparative therapy outcome research: A critical appraisal. Behavioural Psychotherapy, 10, 4-25.

Sheldon, B. (1986). Social work effectiveness experiments: Review and implications. British Journal of Social Work, 16, 223-242.

*Shiels, L., \& Butler, W. (1992). The development of a stress management and relaxation group in an acute teaching hospital. Australian Social Work, $45,27-30$.

*Shulman, L. (1993). Developing and testing a practice theory: An interactional perspective. Social Work, 38, 91-97.

Smith, M. L., \& Glass, G. V. (1977). Meta-analysis of psychotherapy outcome studies. American Psychologist, 32, 752-760.

Smith, M. L., Glass, G. V., \& Miller, T. (1980). The benefits of psychotherapy. Baltimore: Johns Hopkins University Press.

${ }^{*}$ Snow, D. J. (1992). Marital therapy with parents to alleviate behavioral disorders in their children. Research on Social Work Practice, 2, 172-183.

* Stevenson, K. M., Leung, P., \& Cheung, K-f. M. (1992). Competency-based evaluation of interviewing skills in child sexual abuse cases. Social Work Research of Abstracts, 28(3), 1-16.

*Stosny, S. (1994). "Shadows of the heart": A dramatic video for the treatment resistance of spouse abusers. Social Work, 39, 686-694.

${ }^{*}$ Subramanian, K. (1991). Structured group work for the management of chronic pain: An experimental investigation. Research on Social Work Practice, $1,32-45$.

* Sullivan, R, \& Clancy, T. (1990). An experimental evaluation of interdisciplinary training in intervention with sexually abused adolescents. Health \& Social Work, 15, 207-214.

Thomlison, R. J. (1984). Something works: Evidence from practice effectiveness studies. Social Work, $29,51-56$.

Tolson, E. R., Reid, W. J., \& Garvin, C. D. (1994). Generalist practice: A task centered approach. New York: Columbia University Press.

* Toseland, R. W. (1990). Long-term effectiveness of peer-led and professionally led support groups for caregivers. Social Service Review, 64, 308-327.
*'Toseland, R. W., Labrecque, M. S., Goebel, S. T., \& Whitney, M. H. (1992). An evaluation of a group program for spouses of frail elderly veterans. Gerontologist, 32, 382-390.

*Toseland, R. W., Rossiter, C. M., Peak, T., \& Smith, G. C. (1990). Comparative effectiveness of individual and group interventions to support family caregivers. Social Work, 35, 209-217.

*Vera, M. I. (1993). Group therapy with divorced persons: Empirically evaluating social work practice. Research on Social Work Practice, 3, 3-20.

Videka-Sherman, L. (1988). Meta-analysis of research on social work practice in mental health. Social Work, 33, 325-338.

*Walsh, J. (1994). Social support resource outcomes for the clients of two assertive community treatment teams. Research on Social Work Practice, 4, $448-463$.

*Wells, K., \& Whittington, D. (1993). Child and family functioning after intensive family preservation services. Social Service Review, 67, 56-83.

Wolf, F. M. (1986). Meta-analysis: Quantitative methods for research synthesis. Newbury Park, CA: Sage Publications.

Kevin M. Gorey, MSW, PhD, is associate professor, Social Work Program, University of Windsor, 401 Sunset Avenue, Windsor, Ontario, N9B 3P4; e-mail:gorey@server.uwindsor.ca.BruceA. Thyer, PhD, is professor, School of Social Work, University of Georgia, Athens. Debra E. Pawluck, $B S W$, is a PhD candidate, School of Social Work, University of Toronto.

Original manuscript received August 28, 1996

Final revision received January 2, 1997

Accepted February 21, 1997 